\title{
Moral Education (2010-2019): A Bibliometric Study (Part 2)
}

\author{
J. Julia ${ }^{1, *}$, Encep Supriatna ${ }^{1}$, I. Isrokatun ${ }^{1}$, Iis Aisyah ${ }^{2}$, Arif Hakim ${ }^{3}$, Adeola Aminat Odebode ${ }^{4}$ \\ ${ }^{1}$ Elementary Teacher Education Program, Universitas Pendidikan Indonesia, Bandung, Indonesia \\ ${ }^{2}$ Nursing Program, Universitas Pendidikan Indonesia, Bandung, Indonesia \\ ${ }^{3}$ Early Childhood Teacher Education Program, Universitas Islam Bandung, Bandung, Indonesia \\ ${ }^{4}$ Department of Counsellor Education, University of Ilorin, Ilorin, Nigeria
}

Received March 24, 2020; Revised April 18, 2020; Accepted May 3, 2020

Copyright $\bigcirc 2020$ by authors, all rights reserved. Authors agree that this article remains permanently open access under the terms of the Creative Commons Attribution License 4.0 International License

\begin{abstract}
This research seeks to map several significant aspects in moral education bibliography. The mapping of moral education research that covers the country of contributors, collaborating authors, terms used in article titles and abstracts is needed to direct future research. The aim of this article is at classifying and analyzing moral education studies published in reputable international journals during 2010-2019 through a bibliometric study. This study uses the systematic and structured mind mapping method. There are four stages of the study: (1) searching for articles using the Publish or Perish application from the Scopus database, (2) filtering out articles to be included in bibliometric analysis, (3) checking and completing article metadata, and (4) conducting bibliometric analysis using the VOSviewer application. The results of the analysis were: (1) the countries of authors who publish moral education articles. Many countries have contributed in journal publications and the largest contributor is the United States. Analysis results showed that author collaboration did not occur often in moral education articles. (3) The most widely used terms in moral education article titles. The most used term is 'moral education'. (4) The most widely used abstract terms in moral education articles. The most used term in moral education articles is 'moral education'. This study concluded that the research on modal education has been spread in many countries, although the collaboration between institutions or the state is still lacking. Collaboration becomes an opportunity.
\end{abstract}

Keywords Moral Education, Bibliometric Analysis, Bibliographic Review, Ethics and Moral, Publish or Perish, VOSviewer, Publication Trends, Bibliographic Mapping

\section{Introduction}

In the first part of the paper, entitled Moral Education (2010-2019): A Bibliometric Study (Part 1), the authors have analyzed a moral education bibliography from aspects of publication trends, the numbers of contributed citations, journals and publishers, and the most used author keywords. In this paper, we complete the study of moral education from bibliometric analysis to provide a more comprehensive analysis and information with a focus on four other aspects, including the most contributive analysis based on the countries, author collaboration, the most used terms in the title, and the most used terms in abstracts. Therefore, this research is expected to provide broader information to emerge new possibilities in filling the gaps in the area of moral education research.

Based on the literature review, in the 1930s, the moral development of children had been researched as a means of moral education and character education in particular $[1,2]$. However, there are several studies, which revealed that most of these traditional efforts did not have a significant effect on attitudes and behaviors on the effects of widely recognized best teaching practices that emphasize classroom community, intellectual autonomy of students, and high-level academic teaching [3-5].The research on moral and social development has supported that, in addition to obtaining social standards or noble habits, moral education should consider the construction of moral and social judgments of students [6-10]. This indicates that moral concern for justice and human welfare has been formed from an early age to focus on moral education [11-16]. Other studies also show that moral development does not lead to the endpoint, e.g. nonmoral considerations are overwhelmed by moral principles [17-19]. Therefore, moral education varied approaches to prepare students in dealing with moral complexity by considering personal behavior and efforts to create a fair and compassionate community [20-22]. 
Based on the latest research on moral education, Dube and Cias [23] examined the resistance of the religious curriculum in Zimbabwe. They identified the challenges to the new religious curriculum and the role of the international practice of teaching religion in the curriculum in overcoming the contested terrain and improving the policy of inter-religious relations. The results revealed that the religious teaching and learning cannot be handed over to the state; instead, there must be an effort to create a policy of interreligious relations in the context of respecting differences. Religious people need to reconfigure religions in order to face the reality of community's lives.

The study was conducted by Mefodeva et al. [24] on the synthesis of spiritual and moral education through leisure activity. The results revealed that leisure activity is considered to be beneficial in forming life skills, such as fulfilling individual needs in intellectual, cultural and moral development, forming citizenships for children to improve the ability to work and survive in modern civilization, providing learning for children through the experience of generations to make them good citizens, providing equilibrium between spirituality and morality, and preserving and improving the moral, cultural, and scientific values in the community.

The research conducted by Umami, Gani and Waskito [25] proposed character and moral education for gifted young scientists in Indonesia. The results revealed that schools need to be developed as a good learning environment for shaping honest, creative, and friendly attitudes of students with national pride and dignity. In addition, this research concluded that moral education forms a holistic personality, which is indicated by the high moral standards, such speaking, taking action, behaving, thinking, feeling, and working, with output that is in line with the religious values, norms, and morals.

Zulkifli and Hashim [26] researched the effect of Philosophy for Children (P4C) on students' critical thinking. The research employed a quasi-experimental research design involving 27 students in the experimental group and 34 students in the control group. Based on the statistical t-test on critical thinking, the experimental group obtained a higher mean in the post-test compared to the control group. This indicated that $\mathrm{P} 4 \mathrm{C}$ were able to improve their critical thinking. The $\mathrm{P} 4 \mathrm{C}$ practice facilitates students to think or reflect on the consequences of their actions or presumption in their discussion. Simultaneously, the teachers are able to show career development by providing new strategies with new energy and enthusiasm in the classroom.

Regardless of the abundant literature, there has not been any comprehensive bibliometric study on moral education in the last decade especially in Scopus-indexed journals. So far, existing literature seems to ignore bibliometric maps and the clusters to view various aspects of moral education. No bibliometric study on moral education could show the changes in the characteristics of publications. Therefore, a novel bibliometric analysis is needed. The purpose of this study was to find out the general quantity of scientific publications on moral education, and to conduct a bibliometric analysis describing, for example, the characteristics of the most used term in the titles and abstracts.

This kind of investigation is considered essential, because bibliography has gained higher significance in the field of research [27-31]. Furthermore, this study is more reliable by the analysis of productivity (quantity of publication) and visibility (article citation frequency) [32-36]. The bibliometric indicators enable the analysis of the scientific production and their implication qualitatively and quantitatively [37-39]. These indicators can describe the development of research and then validate the decision-making on scientific policies [40-42].

Bibliometrics is a quantitative technique to identify the authorship pattern and the citations in an area in a certain time period. Therefore, it gives an overview into the area's dynamics [43-45]. The significance of bibliographic study review has also been reported [46-48]. From such article reviews, information can be obtained by analyzing most-cited articles and the number of times they have been cited in a field of research [49]. The research community, publishers, and policy makers are increasingly aware that the processes of evaluation are necessary, especially the bibliometric indicators derived from publications by the authors and journal editorial [50-53].

As the basic analysis of publications gaining more importance, this research's purpose is to conduct a bibliometric analysis in the moral education field, and to describe the topographies in general. This analysis of moral education articles was motivated by the fact that these articles are considered as the most popular publications providing current propensity, development, and information in the academic field. A mapping was conducted to bring forth important bibliometric facts in moral education articles to answer the following questions:

Q1: Which countries contribute the most to the publication of moral education research in 2010-2019?

Q2: What is the pattern of author collaboration in moral education research in 2010-2019?

Q3: What are the most used title terms in moral education research in 2010-2019?

Q4: What are the most used abstract terms in moral education research in 2010-2019? 


\begin{tabular}{|c|c|c|c|}
\hline \multicolumn{4}{|l|}{ Scopus search } \\
\hline Authors: & & Years: $2015-2019$ & Search \\
\hline Affiliations: & & & Search Direct \\
\hline Publication name: & Journal & ISSN: & Clear All \\
\hline Title words: & Moral Education & & Revert \\
\hline Keywords: & Moral Education & & New \\
\hline
\end{tabular}

Figure 1. Bibliographic Search in PoP Application

\section{Research Methods}

\subsection{Examination Procedure}

In this study, Publish or Perish (PoP) software was used to search for the bibliographic database. The database source used for the search in PoP was Scopus. Scopus was chosen, because it is a major database providing peer-reviewed publications [54]. Compared to other databases, Scopus has a larger assortment of materials [49, 55], and it has approximately $70 \%$ larger compared to $\operatorname{WoS}[49,56]$. The bibliography searches were limited to the following aspects: (1) the type of bibliography was only journals; (2) the title and author keywords were two words namely "moral education"; and (3) the year is limited to 2010-2019 (last 10 years). Since searching on the Scopus database via PoP was limited to a maximum of 200 articles in one search, the search was carried out twice, namely in 2010-2014 and in 2015-2019. The bibliographic searches were conducted in January 2020. Figure 1 presents the process of searching bibliographies in the PoP application.

The bibliography search results were saved in the EndNote X9 application and saved into a CSV file to be opened in the Excel or Numbers application. The saved files were then checked and the metadata was completed.

\subsection{Bibliography Filter}

The bibliographies to be included in bibliometric analysis were selected. The selection criteria include: (1) having the correct context of moral education; (2) using English; and (3) published by established and reputable bibliographic database publishers or providers. Every bibliography that would be included or excluded from the bibliometric analysis was examined by tracing it into its primary sources. The bibliographies chosen were only journals. Some of the bibliographies that appear in the search process in the PoP application were not selected because they were conference articles, erratum, notes, editorials, review articles, or articles that did not have abstracts.

The initial search results using PoP were 252 bibliographies. After the selection, there were 207 bibliographies. 45 bibliographies were not selected because they did not meet the criteria. Table 1 shows the number of bibliographies from each year based on the searches using the PoP application.
Table 1. Bibliography Selection Results

\begin{tabular}{|c|c|c|c|}
\hline Publication Year & Included & Excluded & Total \\
\hline 2019 & 29 & 9 & 38 \\
\hline 2018 & 29 & 1 & 30 \\
\hline 2017 & 24 & 5 & 29 \\
\hline 2016 & 13 & 2 & 15 \\
\hline 2015 & 19 & 4 & 23 \\
\hline 2014 & 23 & 4 & 27 \\
\hline 2013 & 23 & 8 & 31 \\
\hline 2012 & 15 & 3 & 18 \\
\hline 2011 & 18 & 3 & 21 \\
\hline 2010 & 14 & 6 & 20 \\
\hline Total & 207 & 45 & 252 \\
\hline
\end{tabular}

\subsection{Bibliography Attributes}

In analyzing the selected bibliography, the metadata were completed. The checks include author names, article titles, author keywords, abstracts, years, volumes, issue numbers, pages, affiliations, countries, number of citations, article links, and publishers. After the metadata were complete, the bibliometric analysis began.

\subsection{Bibliometric Analysis}

The bibliometric analysis was conducted on four aspects: (1) the country of the authors who published moral education articles, (2) the author collaboration in moral education articles, (3) the most widely used title terms in moral education articles, and (4) the most widely used abstract terms in moral education articles. To help conducting bibliometric analysis and visualize the results of the analysis, the VOSviewer application was used [57-59]. VOSviewer was utilized since it is efficient to use with huge sets of data and gives various interesting visuals, analysis, and investigations [60-62]. Additionally, VOSviewer can generate maps of publication, authors, or journals derived from networks of co-citation. It can also build maps of keywords from networks [58]. 


\section{Results}

\subsection{Theme 1: Analysis Based on Country}

Table 2 shows 10 countries that published the most articles on moral education indexed by Scopus. The Unites States was in first position, followed by the United Kingdom, and the Russian Federation. Figure 2 shows the distribution of countries of authors who published moral education articles in journals indexed by Scopus. The author's location was obtained from their addresses written in the article. The addresses were converted into coordinates using GPS Visualizer (gpsvisualizer.com) and the coordinates were extracted using Map Maker (maps.co). Figure 3 shows the number of author distributions based on regional clustering which was also extracted from Map Maker.

Table 2. Top Ten Countries that Have Published the Most Articles on Moral Education

\begin{tabular}{|c|c|}
\hline Country & Number of Authors \\
\hline United States & 77 \\
\hline United Kingdom & 40 \\
\hline Russian Federation & 22 \\
\hline Iran & 19 \\
\hline Taiwan & 18 \\
\hline Malaysia & 13 \\
\hline Netherlands & 13 \\
\hline South Africa & 13 \\
\hline Indonesia & 12 \\
\hline China & 11 \\
\hline
\end{tabular}




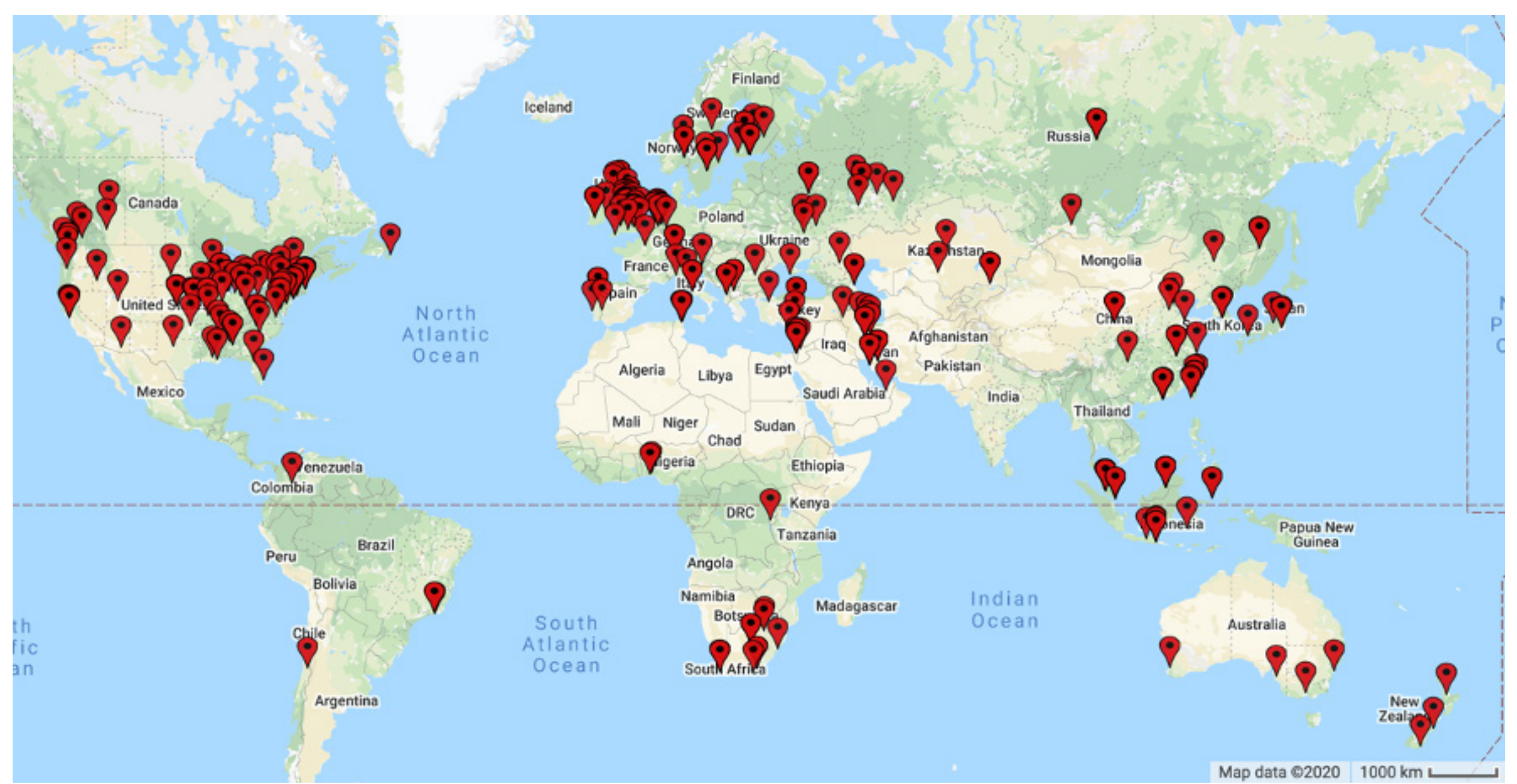

Figure 2. Author Distribution by City/Country Coordinate 


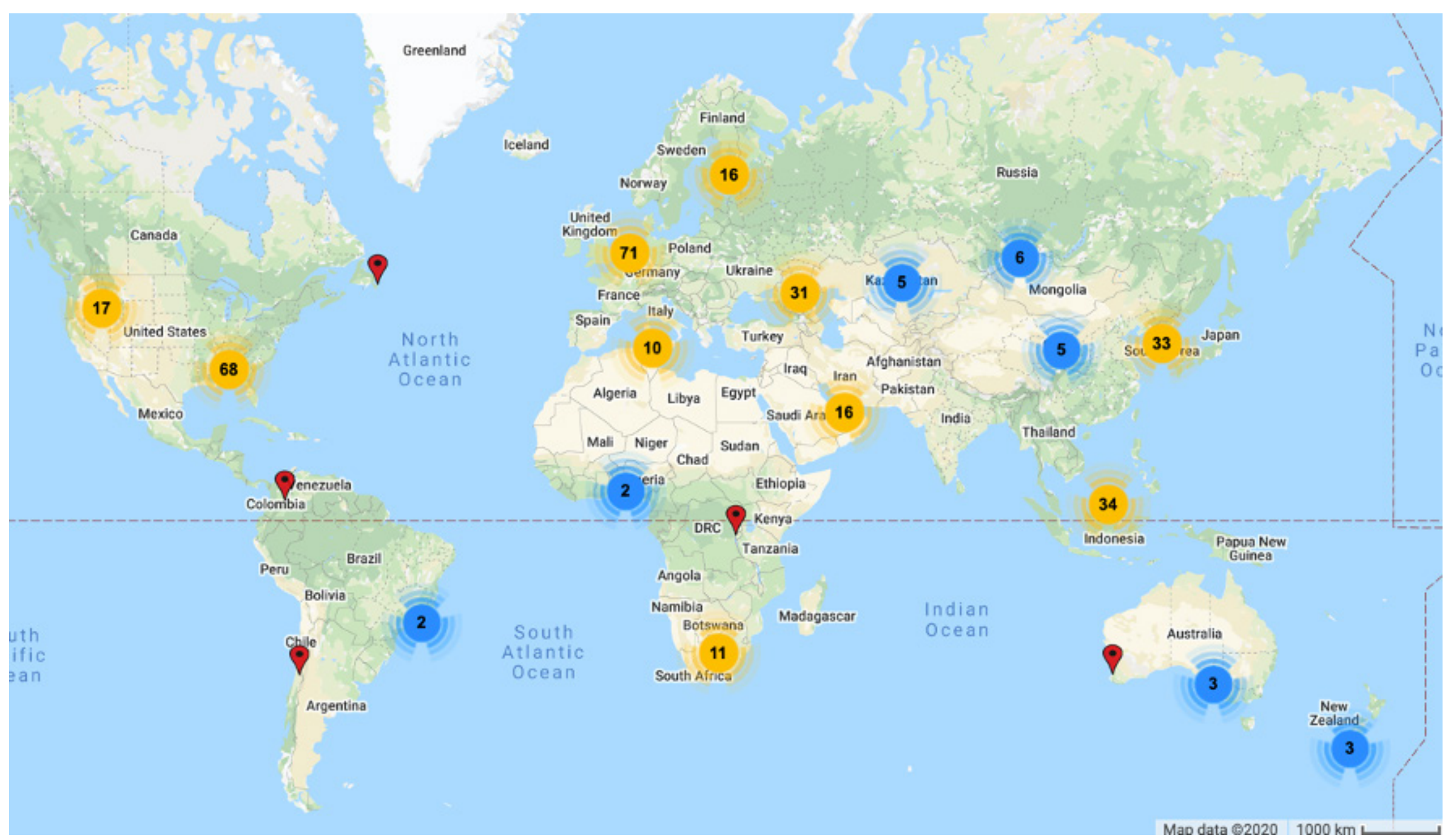

Figure 3. Author Distribution by Regional Clusters 


\subsection{Theme 2: Analysis Based on Author Collaboration}

Of the 412 authors, nine authors had strong associations. As shown in Figure 4 and Table 3, the author's collaboration is divided into two clusters, namely the green and red clusters. Cluster one consists of five authors and cluster two consists of four authors. Each author in cluster one has five links, while the authors incluster two has one, two, three, and seven links. The author who has the most links is Han, $\mathrm{H}$.

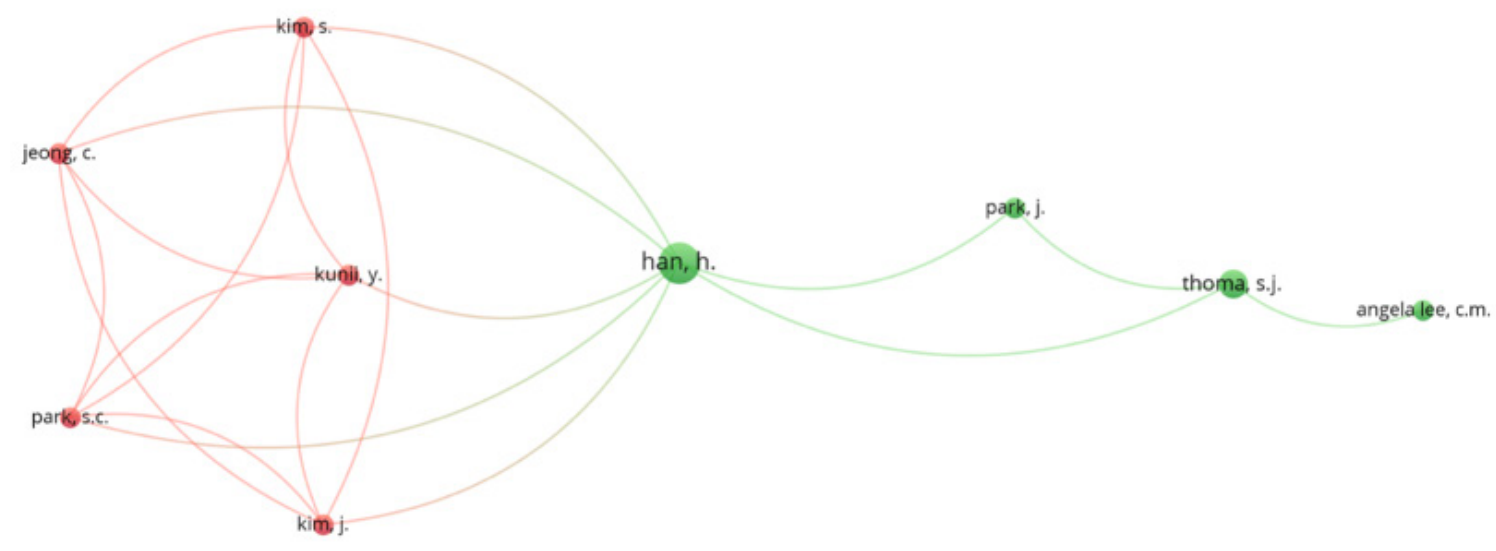

Figure 4. Network Visualization of Author Collaboration

Table 3. Author Clusterization

\begin{tabular}{|c|c|c|c|c|}
\hline Cluster & Color & Author & Number of Documents & Number of Links \\
\hline \multirow{5}{*}{1} & \multirow{5}{*}{ Red } & jeong, c & 1 & 5 \\
\hline & & kim, j & 1 & 5 \\
\hline & & kim, s & 1 & 5 \\
\hline & & kunii, y & 1 & 5 \\
\hline & & park, s.c & 1 & 5 \\
\hline \multirow{4}{*}{2} & \multirow{4}{*}{ Green } & angela lee, c.m & 1 & 1 \\
\hline & & han, h & 4 & 7 \\
\hline & & park, j & 1 & 2 \\
\hline & & thoma, s.j & 2 & 3 \\
\hline
\end{tabular}

\subsection{Theme 3: Analysis Based on Title Term}

Of the 673 terms, using a minimum number of occurrences of three terms, 35 results were found to be relevant. Table 4 and Figure 5 show that the terms widely used in moral education articles are divided into eight clusters. Cluster one consists of eight items, cluster two and three consist of six items, cluster four and five consist of four items, cluster six and seven consist of three items, and cluster eight consists of one item. The most widely used title term in moral education articles is "Moral Education" with a total of 97 in the three term occurrences. 
Table 4. The Most Used Title Term in Moral Education Articles

\begin{tabular}{|c|c|c|l|}
\hline No & Cluster & Number of Item & Terms \\
\hline 1 & One (red) & 8 & $\begin{array}{l}\text { Business education (3); contribution (3); ethics education (9); implication (6); } \\
\text { moral development (8); moral distress (5); practice (6); relevance (3) }\end{array}$ \\
\hline 2 & Two (green) & 6 & $\begin{array}{l}\text { Challenge (6); change (4); development (8); higher education (6); japan (3) } \\
\text { moral reasoning (4) }\end{array}$ \\
\hline 3 & Three (blue) & 6 & $\begin{array}{l}\text { Education (77); moral disengagement (4); moral judgment (4); religion (4); } \\
\text { role (8); study (13) }\end{array}$ \\
\hline 4 & Four (yellow) & 4 & Character education (7); Indonesia (3); reply (3); school (9) \\
\hline 5 & Five (purple) & 4 & Case (5); effect (6); research (5); student (13) \\
\hline 6 & Six (aqua) & 3 & Moral education (97); Taiwan (3); Ubuntu (3) \\
\hline 7 & Seven (orange) & 3 & Content analysis (3); teacher (4); value (11) \\
\hline 8 & Eight (brown) & 1 & Moral (7) \\
\hline
\end{tabular}

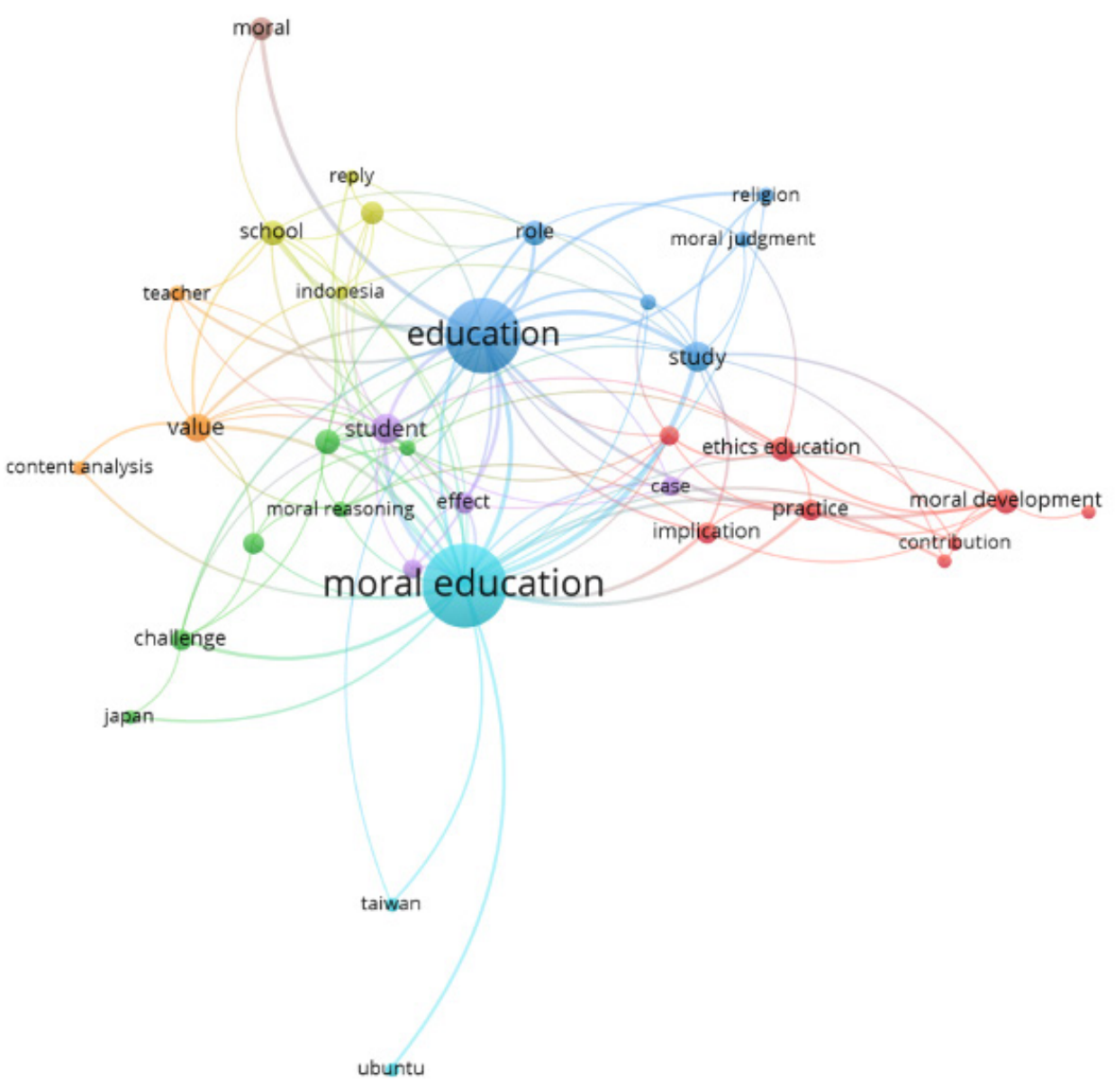

VOSviewer

Figure 5. Network Visualization of Title Terms of Moral Education Articles

\subsection{Theme 4: Analysis Based on Abstract Terms}

From 4,272 terms, with a minimum occurrence number of five terms, a total of 287 results have strong links. Figure 6-8 show the abstract terms in moral education articles that are widely used by writers. In the network visualization, overlay visualization, and density visualization versions, it can be seen that the terms most widely used include: moral education, education, student, school, paper, and practice. 


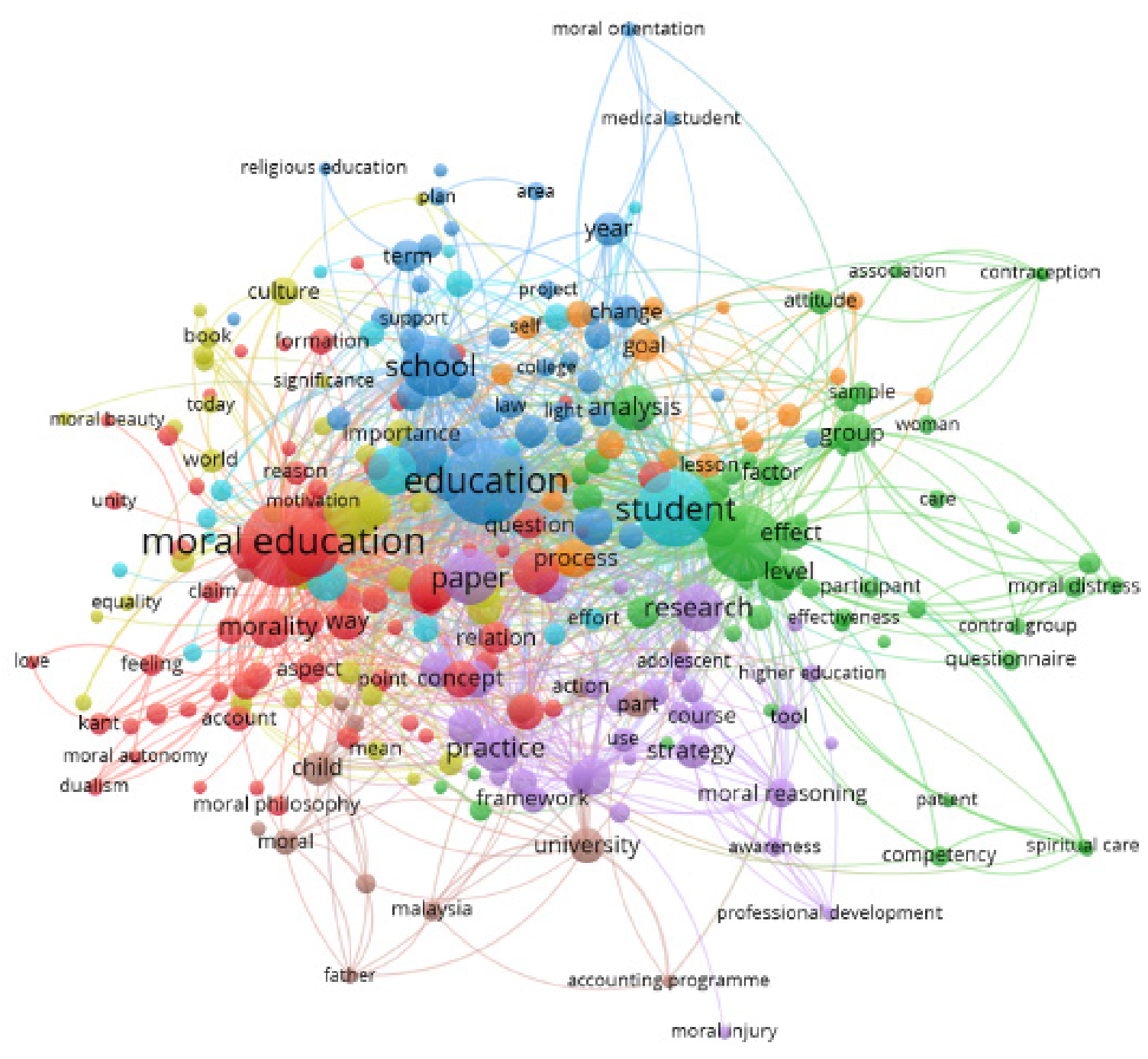

Figure 6. Network of the Most Used Abstract Terms Moral Education Articles 


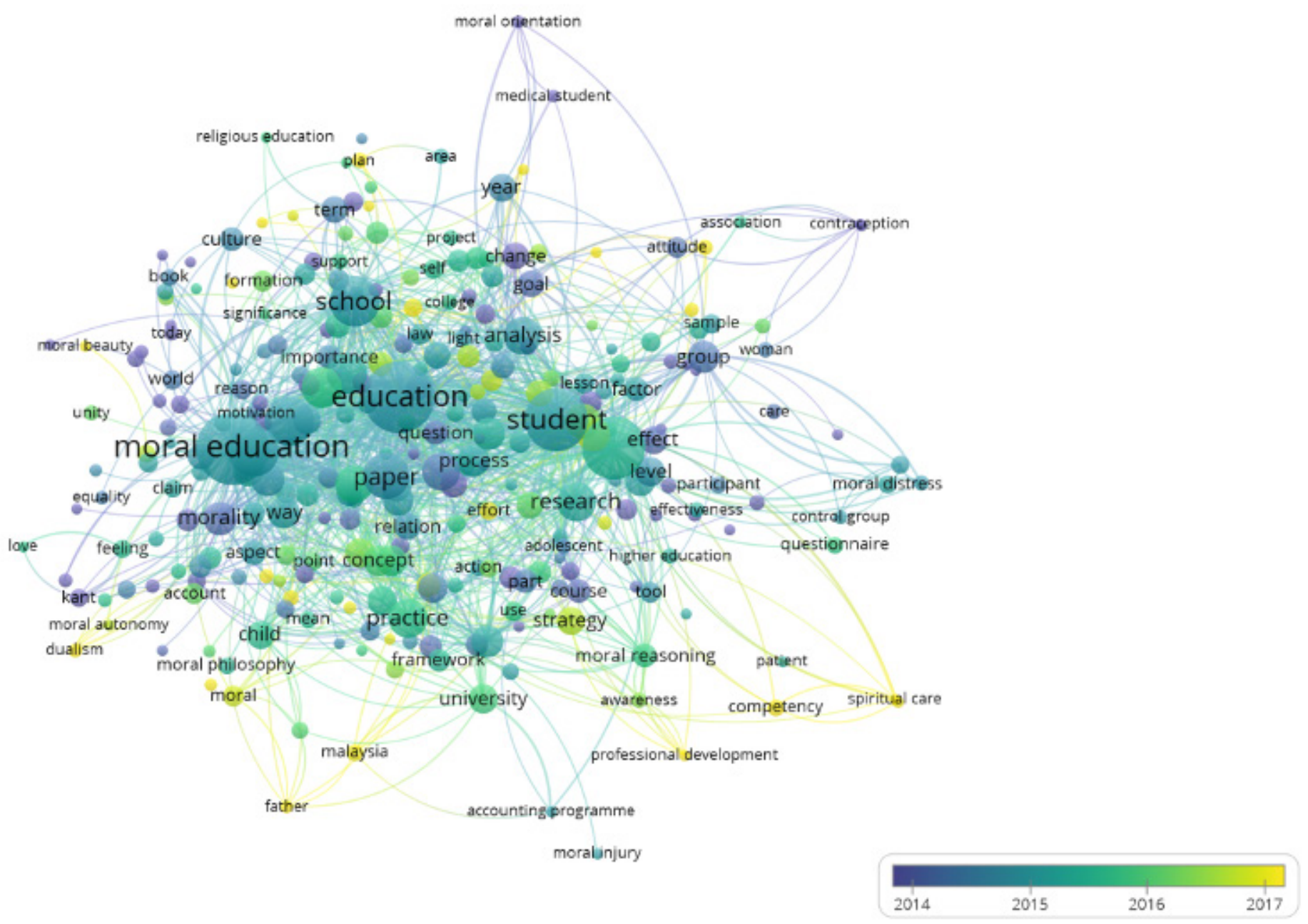

Figure 7. Overlay of the Most Used Abstract Terms Moral Education Articles 


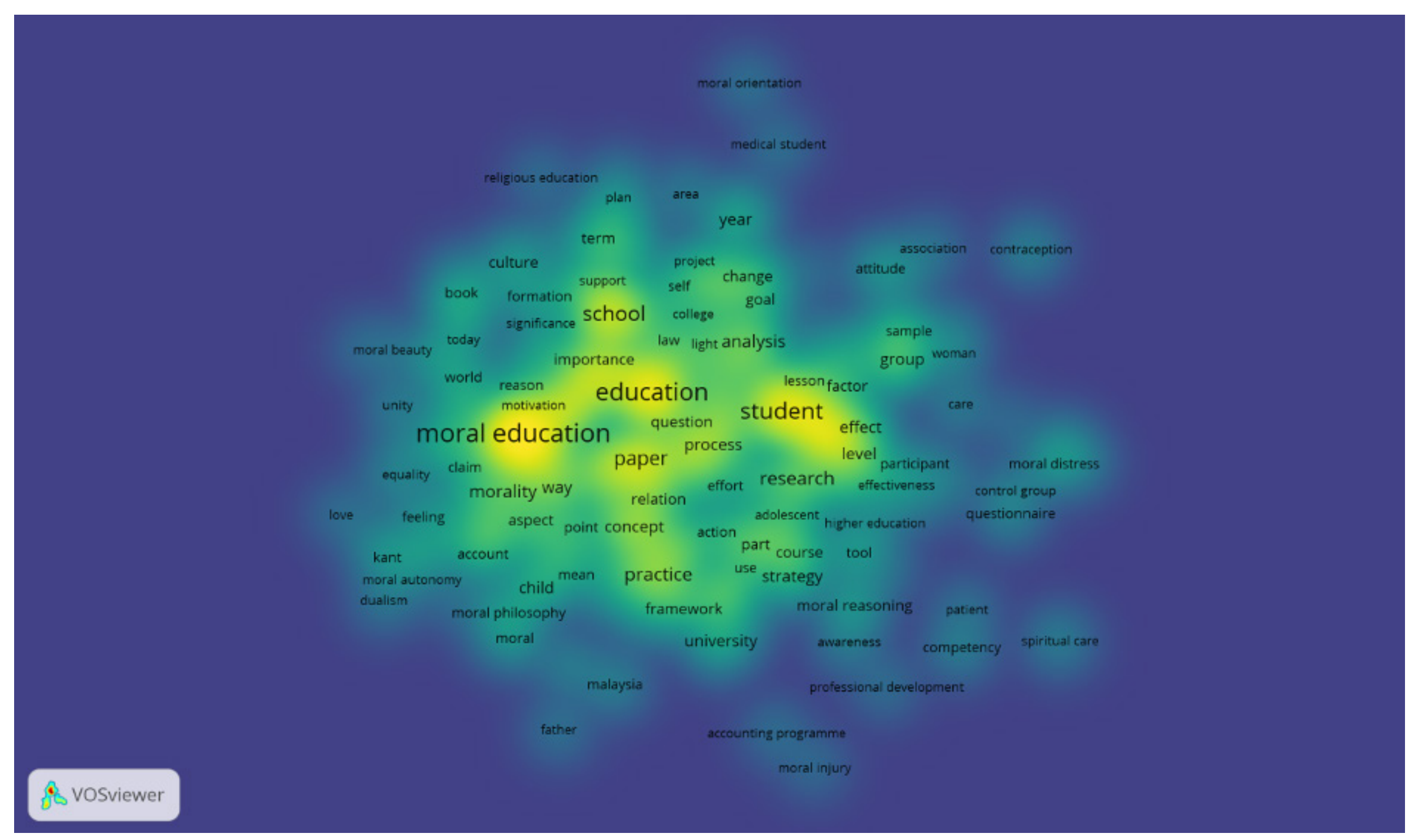

Figure 8. Density of the Most Used in Abstract Terms Moral Education Articles 


\section{Discussion and Conclusions}

The bibliometric analysis results of the four aspects country, author, title term, and abstract term in Scopus indexed moral education articles in 2010-2019 are as follows. When the addresses of the authors listed in moral education articles were extracted in the form of coordinates via the GPS generator, it can be identified that the authors of moral education articles were spread in various countries and continents. The country that published the most articles on moral education was the United States with 77 authors, the United Kingdom with 40 authors, and the Russian Federation with 22 authors, and followed by other countries with less than 22 such as Iran, Taiwan, and others. Based on its regional clusters as shown in Figure 3, the largest cluster was in the United Kingdom and surrounding areas which showed authors in up to 71 cities/countries, such as Adams, Monahan and Wills [10], Arthur and Carr [63], Chester et al. [64], and others. The second largest cluster was in the United States that showed authors in up to 68 cities/countries, such as Felder et al. [65], Grant [66], Hayden [67], and others. Meanwhile, the next group of authors was shown around Indonesia with 34 cities/countries, around Korea with 33 cities/countries, and around Turkey with 31 cities/countries.

Author collaboration analysis showed that Han, H. was the author with the most collaboration. Seven links were formed with Han, H. i.e. Park, J., Thoma, S.J., Kim, J., Park, S.C., Kunii, Y., Jeong, C., and Kim, S. The authors ranked second were Kim, J., Park, S.C., Kunii, Y., Jeong, C., and Kim, S. Then, the third with three links was Thoma, S.J. who had a link with Han, H., Park, J., and Angela Lee, C.M. When viewed from the number of articles, Han, H. was the author having the most collaborative articles with a total of four articles [68-71]. The second was occupied by Thoma, S.J. as the co-author with in a total of two articles [70, 72]. Meanwhile, the other authors only had one article with the position as a co-author, and one person was the main author namely Angela Lee, C.M. This indicated that the author collaboration in moral education articles was relatively small.

Based on the analysis of terms that are often used in the titles of moral education articles, 35 terms had strong links, with the minimum occurrence number of three terms. The five most dominant terms used in the titles were respectively occupied by 'moral education' (97 occurrences), 'education' (77 occurrences), 'student' (13 occurrences), 'study' (13 occurrences), and 'value' (11 occurrences). This implied that the authors had the tendency to use the words 'moral education' in the title, which is the main topic. Some examples are in the articles by Anam et al. [73], Yu [74], D'Olimpio [75]. Likewise, the term 'education' is the second most frequently used term by authors such asOlvitt [76], Walker and Florea [77], and so on. There were also a number of moral education articles that used the term 'student', as in Hsu and Pan [78], or the term 'study' as in Koh [79], or the term 'value' as in Teh and Zulafiat [80].
In the abstract, 287 terms were analyzed to have strong links, with the analysis using the minimum occurrence number of five terms. The analysis showed that the terms were divided into eight clusters as shown in the colors in Figure 6. Cluster one consists of 67 items, cluster two 52 items, cluster three 43 items, cluster four 36 items, cluster five 34 items, cluster six 21 items, cluster seven 19 items, and cluster eight 15 items. The most used term in the abstracts that has relevance between the abstracts was 'moral education' with 203 occurrences. The second was 'education'(196 occurrences), the third was 'student'(151 occurrences), the fourth was 'study'(151 occurrences), the fifth was 'article' (98 occurrences), the sixth was 'school' (97 occurrences), the seventh was 'value' (91 occurrences), the eighth was 'article'( 82 occurrences), the ninth was 'teacher' (64 occurrences), and the tenth was 'development'(63 occurrences). Thus, the term most widely used in the abstract of moral education articles was 'moral education' as the term was also found in the article title.

In conclusion, the four questions asked at the beginning can be answered and concluded as follows. The countries that publish the most moral education articles were the United States, followed by the United Kingdom, and the Russian Federation. Author collaboration in moral education articles did not show much collaboration, only one author is involved with seven other co-authors, and one co-author is involved with two authors. The terms most widely used in moral education articles were 'moral education', 'education', 'student', 'study', and 'value'. The terms most widely used in abstract articles on moral education 'moral education', 'education', 'student', 'study', and 'article'.

\section{Limitations and Suggestions}

This research has limitations in several aspects, namely: (1) the database used for searching the articles was limited to Scopus only; (2) the software used to analyze bibliometrics was only VOSviewer; and (3) the bibliography included were only in the type of journal article based on the information displayed by Scopus. Therefore, to expand the study in this topic, future studies may be able to use several sources/databases, other bibliometric analysis software, and other categories of literature, for instance review papers and book chapters.

\section{REFERENCES}

[1] L Nucci. Moral Education. In: Lafollette H, editor. International Encyclopedia of Ethics: Wiley Online Library; 2013.

[2] A Henning, A Brenick, M Killen, A O'Connor, MJ Collins. Do stereotypic images in video games affect attitudes and behavior? Adolescents' perspectives. Children, youth and 
environments. 2009; 19(1):170.

[3] SCDR Consortium. Efficacy of schoolwide programs to promote social and character development and reduce problem behavior in elementary school children 2010 [2011-01]. Available from: https://ies.ed.gov/ncer/pubs/2011 $2001 /$.

[4] M Almlund, AL Duckworth, J Heckman, T Kautz. Personality psychology and economics. Handbook of the Economics of Education. 4: Elsevier; 2011.p. 1-181.

[5] SM Jones, SM Bouffard. Social and emotional learning in schools: from programs to strategies and commentaries. Social policy report. 2012; 26(4):1-33.

[6] J O'Flaherty, O McCormack. Student holistic development and the 'goodwill' of the teacher. Educational Research. 2019; 61(2):123-41.

[7] L Cooper. "If These Values are not Understood and Accepted..." A Review of the Social Development Curricula. Asia Pacific Journal of Social Work and Development. 2002; 12(1):41-58.

[8] OO Oluwafemi, AH Bibire, VA Mebu, PH Dung, JK Aderibigbe. Conditional indirect effects of gender and school on internet use for academic activities and social-moral development among secondary school students in Nigeria. Cogent Social Sciences. 2020; 6(1):1748478.

[9] L Nucci, MW Creane, DW Powers. Integrating moral and social development within middle school social studies: a social cognitive domain approach. Journal of Moral Education. 2015; 44(4):479-96.

[10] K Adams, J Monahan, R Wills. Losing the whole child? A national survey of primary education training provision for spiritual, moral, social and cultural development. European Journal of Teacher Education. 2015; 38(2): 199-216.

[11] T Krettenauer, S Campbell, S Hertz. Moral emotions and the development of the moral self in childhood. European Journal of Developmental Psychology. 2013; 10(2): 159-73.

[12] G Nunner - Winkler. Development of moral motivation from childhood to early adulthood. Journal of Moral Education. 2007; 36(4):399-414.

[13] G Wilgus. Male early childhood teachers negotiate classroom dilemma: class, family, community and culture in models for moral reasoning. Journal of Gender Studies. 2009; 18(3): 215-30.

[14] JH Ruckert. Justice for All? Children's Moral Reasoning about the Welfare and Rights of Endangered Species. Anthrozoös. 2016; 29(2): 205-17.

[15] R DeVries, B Zan, C Hildebrandt. Issues in Constructivist Early Moral Education. Early Education and Development. 2002; 13(3): 313-44.

[16] JC Wright, T Sedlock, J West, K Saulpaugh, M Hopkins. Located in the thin of it: Young children's use of thin moral concepts. Journal of Moral Education. 2016; 45(3): 308-23.

[17] F Cushman, L Young. Patterns of Moral Judgment Derive From Nonmoral Psychological Representations. Cognitive Science. 2011; 35(6): 1052-75.

[18] I Morrisson. Moral and Nonmoral Freedom in Kant. The
Southern Journal of Philosophy. 2007; 45(1):129-48.

[19] TS Rai, KJ Holyoak. Moral Principles or Consumer Preferences? Alternative Framings of the Trolley Problem. Cognitive Science. 2010; 34(2):311-21.

[20] D Narvaez. Moral Complexity: The Fatal Attraction of Truthiness and the Importance of Mature Moral Functioning. Perspectives on Psychological Science. 2010; 5(2): 163-81.

[21] SJ Reynolds, TL Ceranic. The effects of moral judgment and moral identity on moral behavior: An empirical examination of the moral individual. Journal of Applied Psychology. 2007; 92(6): 1610-24.

[22] MW Berkowitz, JH Grych. Fostering Goodness: teaching parents to facilitate children's moral development. Journal of Moral Education. 1998; 27(3):371-91.

[23] B Dube, T Cias. State-based curriculum making in a post colonial Zimbabwe: Making sense of Family, Religious and Moral Education in a global context. Journal of Social Studies Education Research. 2019; 10(1):241-58.

[24] M Mefodeva, S Karakozov, R Shakirzyanova, A Eveleva. Integration of Spiritual and Moral Education Using Leisure Activity. Journal of Sociology and Social Anthropology. 2019; 10(4):180-5.

[25] I Umami, A Gani, T Waskito. Proposal of Character and Moral Education for Gifted Young Scientists in Indonesia. Journal for the Education of Gifted Young Scientists. 2019; 7(2): 377-87.

[26] H Zulkifli, R Hashim. Philosophy for Children (P4C) in Improving Critical Thinking in a Secondary Moral Education Class. International Journal of Learning, Teaching and Educational Research. 2020; 19(2): 29-45.

[27] A Friedlander. The implications of information technology for scientific journal publishing: a literature review: National Science Foundation; 2003.

[28] B Cronin. Scholarly communication and epistemic cultures. New review of academic librarianship. 2003;9(1):1-24.

[29] C Tenopir, DW King, J Spencer, L Wu. Variations in article seeking and reading patterns of academics: What makes a difference? Library \& Information Science Research. 2009; 31(3): 139-48.

[30] DW King, C Tenopir, S Choemprayong, L Wu. Scholarly journal information - seeking and reading patterns of faculty at five US universities. Learned Publishing. 2009; 22(2): 126-44.

[31] C Tenopir, R Mays, L Wu. Journal article growth and reading patterns. New Review of Information Networking. 2011; 16(1): 4-22.

[32] M Bordons. Evaluación de la actividad científica a través de indicadores bibliométricos [Evaluation of scientific activity through bibliometric indicators]. Revista española de cardiología. 1999; 52(10):790-800.

[33] F De-Moya-Anegón, Z Chinchilla-Rodríguez, E Corera-Álvarez, FJ Muñoz-Fernández, J Navarrete-Cortés. Indicadores bibliométricos de la actividad científica española:(ISI, Web of science, 1998-2002) [Bibliometric indicators of Spanish scientific activity: (ISI, Web of science, 1998-2002)]: FECYT-Ministerio de Educación y Ciencia, 
Spain; 2004.

[34] F López-Muñoz, C Alamo, FJ Quintero-Gutiérrez, P García-García. A bibliometric study of international scientific productivity in attention-deficit hyperactivity disorder covering the period 1980-2005. European child \& adolescent psychiatry. 2008; 17(6): 381-91.

[35] F López-Muñoz, P García-García, J Sáiz-Ruiz, J Mezzich, G Rubio, E Vieta, et al. A bibliometric study of the use of the classification and diagnostic systems in psychiatry over the last 25 years. Psychopathology. 2008; 41(4):214-25.

[36] J Ramos, F Gutierrez, M Masia, A Martin-Hidalgo. Publication of European Union research on infectious diseases (1991-2001): a bibliometric evaluation. European Journal of Clinical Microbiology and Infectious Diseases. 2004; 23(3):180-4.

[37] B Velasco, JME Bouza, JM Pinilla, JA San Román. La utilización de los indicadores bibliométricos para evaluar la actividad investigadora. Aula abierta. 2012; 40(2):75-84.

[38] JN Cudina, JC Ossa. The top 100 high-impact papers in Colombian psychology: a bibliometric study from WoS and Scopus. Informação \& Sociedade. 2016; 26(2).

[39] R Quevedo-Blasco, T Ariza. Twenty-five year history of the journal Psicothema. Psicothema. 2013; 25(1):93-9.

[40] P Cunningham. The evaluation of european programmes and the future of scientometrics. Scientometrics. 1997; 38(1): $71-85$.

[41] R Panat. On the data and analysis of the research output of India and China: India has significantly fallen behind China. Scientometrics. 2014; 100(2): 471-81.

[42] JMF Batanero, MMR Rebollo, MM Rueda. Impact of ICT on students with high abilities. Bibliographic review (20082018). Computers \& Education. 2019; 137: 48-58.

[43] AR Mathankar. Bibliometrics: An overview. International Journal of Library \& Information Science (IJLIS). 2018;7(3):9-15.

[44] İ Şeref, B Karagöz. A bibliometric profile of literature of Turkish language education-teaching: A case study of 9th International Language Education-Teaching Conference. European Journal of Alternative Education Studies. 2019.

[45] İ Şeref, B Karagöz. An Evaluation of Turkish Education Academic Field: Bibliometric Analysis Based on Web of Science Database [Türkçe Eğitimi Akademik Alanına İlişkin Bir Değerlendirme: Web of Science Veri Tabanına Dayalı Bibliyometrik İnceleme]. Journal of Language Education and Research. 2019; 5(2): 213-31.

[46] JM Fernández Batanero, M Montenegro Rueda, J Fernández Cerero, I García Martínez. Impact of the Information and Communication Technologies on the Education of Students with Down Syndrome: a Bibliometric Study (2008-2018). European Journal of Educational Research, 9 (1), 79-89. 2019.

[47] EJ Beh. Simple correspondence analysis: a bibliographic review. International Statistical Review. 2004; 72(2): 257-84.

[48] A Rouilly, L Rigal. Agro-materials: a bibliographic review. Journal of Macromolecular Science, Part C: Polymer Reviews. 2002; 42(4):441-79.
[49] M Shareefa, V Moosa. The Most-cited Educational Research Publications on Differentiated Instruction: A Bibliometric Analysis. European Journal of Educational Research. 2020; 9(1):331-49.

[50] HF Moed. Citation analysis in research evaluation: Springer Science \& Business Media; 2006.

[51] HF Moed. New developments in the use of citation analysis in research evaluation. Archivum immunologiae et therapiae experimentalis. 2009; 57(1):13.

[52] LI Meho, K Yang. Impact of data sources on citation counts and rankings of LIS faculty: Web of Science versus Scopus and Google Scholar. Journal of the american society for information science and technology. 2007; 58(13):2105-25.

[53] AF Van Raan. Comparison of the Hirsch-index with standard bibliometric indicators and with peer judgment for 147 chemistry research groups. scientometrics. 2006; 67(3): 491-502.

[54] BS Ballew. Elsevier's Scopus ${ }^{\circledR}$ Database. Journal of Electronic Resources in Medical Libraries. 2009; 6(3): 245-52.

[55] L Salisbury. Web of Science and Scopus: A comparative review of content and searching capabilities. The Charleston Advisor. 2009; 11(1): 5-18.

[56] C López-Illescas, F de Moya-Anegón, HF Moed. Coverage and citation impact of oncological journals in the Web of Science and Scopus. Journal of informetrics. 2008; 2(4): 304-16.

[57] FJ Martínez-López, JM Merigó, JC Gázquez-Abad, JL Ruiz-Real. Industrial marketing management: Bibliometric overview since its foundation. Industrial Marketing Management. 2019.

[58] MN Hudha, I Hamidah, A Permanasari, AG Abdullah, I Rachman, T Matsumoto. Low Carbon Education: A Review and Bibliometric Analysis. European Journal of Educational Research. 2020; 9(1): 319-29.

[59] N Shukla, JM Merigó, T Lammers, L Miranda. Half a century of Computer Methods and Programs in Biomedicine: A bibliometric analysis from 1970-2017. Computer methods and programs in biomedicine. 2019:105075.

[60] N Van Eck, L Waltman. Software survey: VOSviewer, a computer program for bibliometric mapping. scientometrics. 2010; 84(2): 523-38.

[61] NJ Van Eck, L Waltman. Visualizing bibliometric networks. Measuring scholarly impact: Springer; 2014. p. 285-320.

[62] I Rafols, L Leydesdorff, A O’Hare, P Nightingale, A Stirling. How journal rankings can suppress interdisciplinary research: A comparison between innovation studies and business \& management. Research policy. 2012; 41(7): 1262-82.

[63] J Arthur, D Carr. Character in learning for life: A virtue-ethical rationale for recent research on moral and values education. Journal of Beliefs and Values. 2013; 34(1): 26-35.

[64] KL Chester, E Klemera, J Magnusson, NH Spencer, FM Brooks. The role of school-based health education in adolescent spiritual moral, social and cultural development. Health Education Journal. 2019; 78(5): 582-94. 
[65] P Felder, K Kline, D Harmening, T Moore, EP St John. Professional development and moral reasoning in higher education graduate programs. International Journal of Doctoral Studies. 2019; 14: 383-401.

[66] F Grant. Mechanical experiments as moral exercise in the education of George III. British Journal for the History of Science. 2015; 48(2): 195-212.

[67] MJ Hayden. The Process Matters: Moral Constraints on Cosmopolitan Education. Journal of Philosophy of Education. 2017; 51(1): 248-66

[68] H Han. Analysing theoretical frameworks of moral education through Lakatos's philosophy of science. Journal of Moral Education. 2014; 43(1): 32-53.

[69] H Han. The VIA inventory of strengths, positive youth development, and moral education. Journal of Positive Psychology. 2019; 14(1): 32-40.

[70] H Han, J Park, SJ Thoma. Why do we need to employ Bayesian statistics and how can we employ it in studies of moral education?: With practical guidelines to use JASP for educators and researchers. Journal of Moral Education. 2018;47(4):519-37.

[71] H Han, SC Park, J Kim, C Jeong, Y Kunii, S Kim. A quantitative analysis of moral exemplars presented in moral education textbooks in Korea and Japan. Asia Pacific Journal of Education. 2018;38(1):62-77.

[72] CM Angela Lee, SJ Thoma. Developing and testing a scale of moral thinking and communication (MTC) functioning: a preliminary study and its implications for moral development and education. Asia Pacific Journal of Education. 2018; 38(1):32-50.

[73] S Anam, INS Degeng, N Murtadho, D Kuswandi. The moral education and internalization of humanitarian values in pesantren. Journal for the Education of Gifted Young Scientists. 2019; 7(4):815-34.

[74] YM Yu. Comparing Moral Education Models at a Military Academy in Taiwan. Journal of Academic Ethics. 2018; 16(2): 173-93.

[75] L D'Olimpio. Moral education within the social contract: Whose contract is it anyway? Journal of Moral Education. 2019; 48(4): 515-28.

[76] LL Olvitt. Education in the Anthropocene: Ethico-moral dimensions and critical realist openings. Journal of Moral Education. 2017; 46(4): 396-409.

[77] RL Walker, L Florea. Easy-Come-Easy-Go: Moral Hazard in the Context of Return to Education. Journal of Business Ethics. 2014; 120(2): 201-17.

[78] WT Hsu, YH Pan. Moral disengagement and student misbehavior in physical education. Journal of Sports Science and Medicine. 2018; 17(3): 437-44.

[79] C Koh. Moral development and student motivation in moral education: A Singapore study. Australian Journal of Education. 2012; 56(1): 83-101.

[80] KSM Teh, Zulafiat. Value and moral education approach of Ka seto homeschooling in Jakarta, Indonesia. Journal of Legal, Ethical and Regulatory Issues. 2019; 22(5): 1-6. 